\title{
552 超弾性・粘性モデルによる織布補強ゴムのカ学特性モデリング
}

\author{
Modeling of a textile-reinforced rubber mechanical properties \\ by using a visco-hyperelastic model
}
○正 浅井光輝（九州大）
西本安志 (シバタ工業(株))
園田佳巨（九州大）

木村嘉之（九州大）

\begin{abstract}
Mitsuteru ASAI, Kyushyu University, 744 motooka,nishi-ku,fukuoka
Yoshiyuki KIMURA, Kyushu University

Yasushi NISHIMOTO, SHIBATA Industrial Co., LTD., 1058 nakao, uozumi, akashi

Yoshio NISHINO, SHIBATA Industrial Co., LTD.

Yoshimi SONODA, Kyushu University
\end{abstract}

Key Words : Visco-hyperelasticity, Large deformation, Textile reinforced rubber, Anisotropy

\section{1. 緒言}

本研究では, Fig.1 に示すような織布により補強したゴムの 巨視的な材料のモデル化を行った。この材料の静的な材料挙 動は，異方性を示す非線形弾性を示すため，異方性超弾性モ デルによるモデル化を試みた．また，動的挙動に関しては， 強い速度依存性を示すことが過去の研究より予想されてお り，粘性モデルを導入することで対応することとした。

また, 上記モデルの検証ために, 円孔板の重鍾式引張り試 験を行い, 数值解析結果と実験との比較検証を行った.

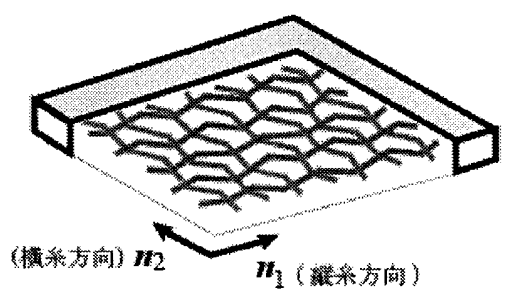

Fig. 1 Fiber reinforced rubber

\section{2. 異方性・粘性超弾性モデルの概要}

\section{1 異方性を含んだ超弾性モデル}

ゴム材料は特有な非線形弾性挙動を示し，しばしば Ogden モデルあるいは Mooney-Rivlin モデルなどの超弾性体として モデル化される. 本研究では, 次式に示す Mooney-Rivlin モ デルをベースとした異方性モデルを採用し，ひずみエネルギ 関数が次式により与えられるものとした.

$$
\begin{aligned}
& W=W_{\text {vol }}+W_{\text {iso }}^{\mathrm{r}}+W_{\text {iso }}^{\mathrm{f}_{1}}+W_{\text {iso }}^{\mathrm{f}_{2}} \\
& W_{\text {vol }}(J)=p(J-1) \\
& W_{\text {iso }}^{\mathrm{r}}\left(\bar{I}_{1}, \bar{I}_{2}\right)=c_{10}\left(\bar{I}_{1}-3\right)+c_{01}\left(\bar{I}_{2}-3\right)+c_{11}\left(\bar{I}_{1}-3\right)\left(\bar{I}_{2}-3\right) \\
& W_{\text {iso }}^{\mathrm{f}_{1}}\left(\bar{I}_{4}\right)=d_{1}\left(\bar{I}_{4}-3\right)^{a_{1}} \\
& W_{\text {iso }}^{\mathrm{f}_{1}}\left(\bar{I}_{5}\right)=d_{2}\left(\bar{I}_{5}-3\right)^{a_{2}}
\end{aligned}
$$

ここで， $c_{i}$ は MooneyーRivlin 定数を示し， $d_{i}, a_{i}$ はそれぞれ 2 方向の繊維に関連する材料パラメータである. なお, 変形 を体積成分と等容成分に分離して考えるものとし，等容変形 に相当する変形勾配テンソル $\mathbf{F}$ の等容成分 $\overline{\mathbf{F}}$ は次式により 与えられるものしている.

$$
\mathbf{F}=J^{1 / 3} \overline{\mathbf{F}}
$$

ここで, $J$ は全変形勾配テンソル Fより評価されるヤコビア
ンである.また，式(1)に示す $\bar{I}_{i}$ は $\overline{\mathbf{F}}$ のみから評価する修正右 コーシー・グリーン変形テンソル $\overline{\mathbf{C}}$ の不変量である. 以下に, その定義をまとめて示す。

$$
\begin{aligned}
& \bar{I}_{1}=\operatorname{tr} \overline{\mathbf{C}} \\
& \bar{I}_{2}=\frac{1}{2}\left\{(\operatorname{tr} \overline{\mathbf{C}})^{2}-\left(\operatorname{tr} \overline{\mathbf{C}}^{2}\right)\right\} \\
& \bar{I}_{4}=\mathbf{n}_{1} \cdot \overline{\mathbf{C}} \mathbf{n}_{1} \\
& \bar{I}_{5}=\mathbf{n}_{2} \cdot \overline{\mathbf{C}} \mathbf{n}_{2}
\end{aligned}
$$

ここで， $\mathbf{n}_{i}$ は繊維軸方向を示す単位ベクトルである.

ひずみエネルギ関数がテンソル $\overline{\mathbf{C}}$ の不変量により表記さ れれば, あとは通常の手順により Cで偏微分することで第 2Piola-Kirchhoff 忘力 $\mathbf{S}(:=2 \partial W / \partial \mathbf{C})$ が定義され, 再度偏微分 することでにより接線係数 $\mathbf{D}\left(:=4 \partial^{2} W / \partial \mathbf{C}^{2}\right)$ が評価できる. (具体的な中身は文献 1) を参照)

本研究では, MSC.Marcによりトータルラグランジュ法に 基づく FE 解析を実施するものとし，上記に示す応力および 接線係数をユーザ定義関数により評価した。

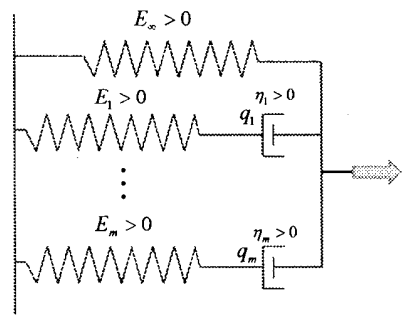

Fig.2 Schematic image of the generalized Maxwell model

3. 有限変形 Maxwell 粘性モデルと異方性粘性モデル

Holzapfel により提案された有限変形に拡張した一般化 Maxwell 粘性モデルを概説し，それを拡張した異方性粘性モ デルを紹介する.

\section{1 等方性粘性モデル}

一般化 Maxwell 粘性モデルとは, Fig.2 に示すように, 直 列に結ばれたバネとダッシュポットの組みが並列につなが れたモデルにより粘弾性特性を表現する構成モデルである. はじめに応力を体積変形成分 $\mathbf{S}_{\mathrm{vol}}=2 \partial W_{\mathrm{vol}} / \partial \mathrm{C}$ と等容変形成 分 $\mathbf{S}_{\text {iso }}=2 \partial W_{\text {iso }} / \partial \mathbf{C}$ 加算分解し, 等容成分は静的応力 $\mathbf{S}_{\text {iso }}^{\infty}$ と非 平衡応力 $\mathbf{Q}_{\alpha}$ の和として表現されるものと仮定する. 


$$
\mathbf{S}_{\mathrm{iso}}=\mathbf{S}_{\mathrm{iso}}^{\infty}+\sum_{\alpha=1}^{m} \mathbf{Q}_{\alpha}
$$

ここで, 非平衡応力 $\mathbf{Q}_{\alpha}$ の時間発展則は, 緩和時間 $\tau_{\alpha}$ と $\mathbf{S}_{\mathrm{iso}}^{\infty}$ か ら次式により与えられる。

$$
\dot{\mathbf{Q}}_{\alpha}+\frac{\mathbf{Q}_{\alpha}}{\tau_{\alpha}}=\beta_{\alpha} \mathbf{S}_{\text {iso }}^{\infty}
$$

ここで， $\mathbf{Q}_{\alpha}$ の初期値はゼロであり, 以降の時間発展は中央 差分法による数値積分により評価した. なお,この時間積分 と整合した接線係数の評価方法の詳細は文献1)に委悋る。

\section{2 異方性粘性モデル}

式(1)に示した異方性モデルのひずみエネルギ関数におい て，等容変形に関与する項は，ゴムに対応した成分 $W_{\text {iso }}^{r}$ と繊 維に対応した成分 $W_{\mathrm{iso}}^{\mathrm{f}_{\mathrm{f}}}, W_{\mathrm{iso}}^{\mathrm{f}_{2}}$ の和として表現されている. 同様 に, 応カテンソルもひずみエネルギの各項を $\mathbf{C}$ で微分した值 の和として表せる。

$$
\begin{aligned}
& \mathbf{S}_{\mathrm{iso}}^{\infty}=\mathbf{S}_{\mathrm{iso}}^{\mathrm{r}}+\mathbf{S}_{\mathrm{iso}}^{\mathrm{f}_{1}}+\mathbf{S}_{\mathrm{iso}}^{\mathrm{f}_{2}} \\
& \mathbf{S}_{\text {iso }}^{\mathrm{r}}=2 \partial W_{\text {iso }}^{\mathrm{r}} / \partial \mathbf{C} \\
& \mathbf{S}_{\mathrm{iso}}^{f_{i}}:=2 \partial W_{\text {iso }}^{f_{i}} / \partial \mathbf{C}
\end{aligned}
$$

ここで, 式(4),(5)を参考にし, 応カテンソルを構成する各 要素に対して, それぞれ非平衡応力を定義することで, 異方 性粘性モデルへと発展できる.

$$
\dot{\mathbf{Q}}_{\alpha}^{m}+\frac{\mathbf{Q}_{\alpha}^{m}}{\tau_{\alpha}^{\mu}}=\beta_{\alpha}^{\mu} \mathbf{S}_{\text {iso }}^{m},\left(m=r, f_{1}, f_{2}\right)
$$

\section{4. 円孔板の重錘引張り試験の数値解}

Fig.3 に示す円孔板の引張り試験結果と比較検証するこ とで, 構成モデルの妥当性を検証した。. 同図には, 平織り織 布の㵶維方向 $\mathbf{n}_{i}$ を, 鉛直方向から $30^{\circ}, 45^{\circ}$ 傾けた場合の実 験結果との比較結果を示している. 方向に依存する織布補強 ゴムの変形特性が. 異方性モデルにより再現できていること が確認できる. 使用したパラメータ一覧を Table.1 に示す. これらは, 別途実施した強化ゴムの一軸引張り試駼結果より 同定した材料パラメータである。（詳細は文献 2) を参照）

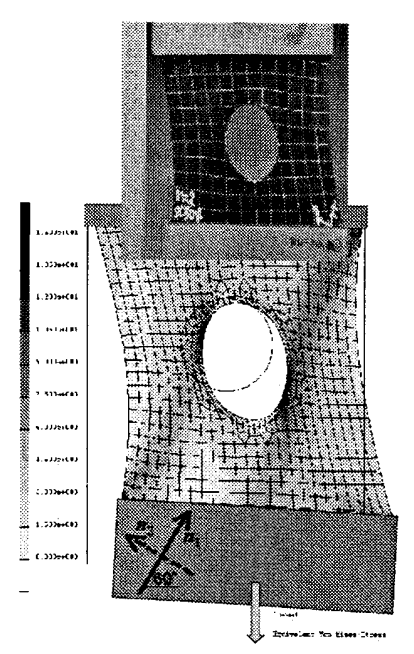

(a) $30^{\circ}$ rotation

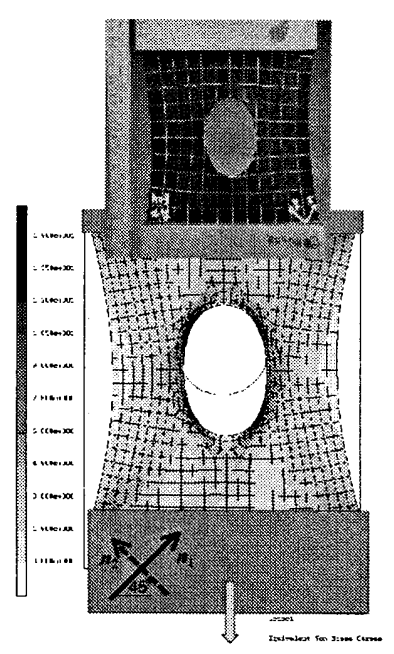

(b) $45^{\circ}$ rotation
Fig. 3 Experimental result in a tension test of rubber sheet with hole
Table.1 Material parameters

\begin{tabular}{|c||c|c|c|}
\multicolumn{5}{c}{ Table.1 Material parameters } \\
\begin{tabular}{|c|c|c|c|}
\hline & $c_{10}[\mathrm{MPa}]$ & $c_{01}[\mathrm{MPa}]$ & $c_{11}[\mathrm{MPa}]$ \\
\hline rubber & 1.03 & -0.55 & 0.04 \\
\hline & $d_{1}[\mathrm{MPa}]$ & $a_{1}$ & - \\
\hline fiber1 $\left(n_{1}\right)$ & 15.5 & 2 & - \\
\hline fiber2 $\left(\boldsymbol{n}_{2}\right)$ & 25.5 & 2 & - \\
\hline
\end{tabular}
\end{tabular}

Fig.4には, 粘性モデルを導入し, 荷重速度を変化させた数 值実験を行った際の荷重変位関係図を示す.また Fig.5には, Fig.4に示した解析の後, $100[\mathrm{~s}]$ の間, 荷重値を最終值のまま キープした前後の状態におけるひずみコンター図を示して いる.

荷重変位関係図が示しているように, 載荷速度を上げるほ ど硬化することが再現できている．また，Fig.5に示すひずみ 分布の推移より, ゴム系材料において顕著となるクリープ変 形が定性的に表現できていることを確認した。なお，このク リープ変形は静的解析の結果へと収束している.

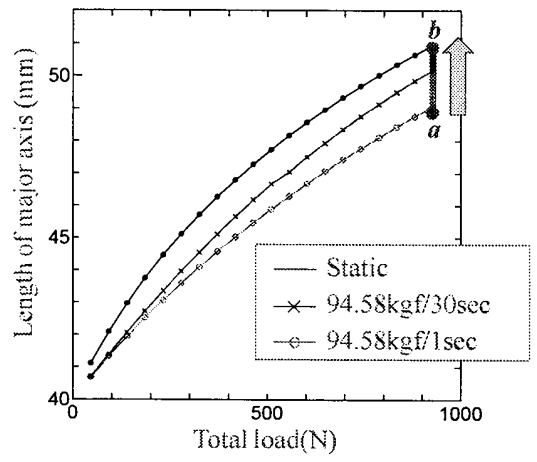

Fig. 4 Load-deformation curves in the loading control test with different loading rates

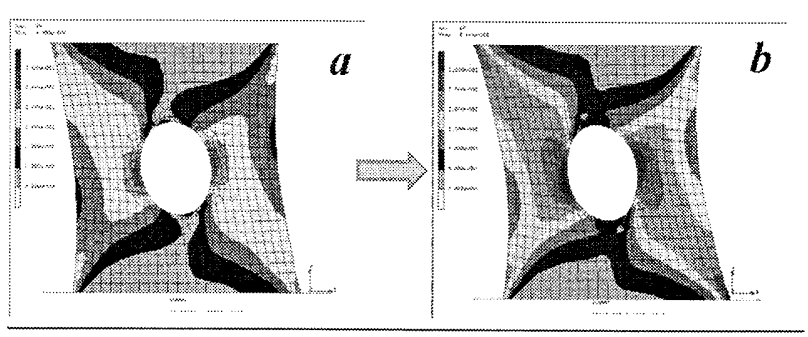

Fig. 5 Equivalent strain distribution during the creep process

\section{5. 結語}

超弾性体モデルの範疇から発展した異方性モデル，および 粘性モデルを用い，織布により補強されたゴムの構造解析に おいて有用な巨視的な材料モデルの構筑を行った.

本稿では, 異方性および粘性モデル可能性の一端を示すこ とができた. 今後, 多数の材料パラメー夕を効率よく同定す るための手順を確立することが望まれる.

\section{参考文献}

1) Holzapefel, G.A. : Nonlinear Solid Mechanics, -A continuum approach for engineers', Wiley, Chichester 2000

2）浅井光輝, 木村嘉之, 西本安志, 西野好生, 園田佳巨 : 異方性超弾性モデルによる織布強化ゴム特性の数值解, 土木学会・応用力学論文集, Vol.11, 467-474 